\title{
Experimental and Theoretical Study of Hardness and Grain Size Variation in Cold Upset for Pure Copper Cylinder
}

\author{
Abdul AlKareem F. Hassan *, Safa A. Saleh, Zainab H. Jibar \\ Materials Engineering Dept.-College of Engineering -University of Basra, Iraq
}

Copyright (C) 2015 Horizon Research Publishing All rights reserved.

\begin{abstract}
In this work, the influence of varied deformation percentages on the hardness and grain size, effective strain variation during simple upsetting is studied. Also, hardness variation in a typical cold upset forging process is predicted by relating hardness and effective strain evolution in a simple upsetting operation empirically. Five different deformation percentages, $(13 \%, 17 \%, 32.4 \%, 41 \%$, $50 \%$ ), are considered for experimentation. Ring compression tests were conducted to determine the friction factor " $m$ ". The upset-forging tests were conducted at room temperate and for different deformation percentage on the pure copper cylindrical specimens of $30 \mathrm{~mm}$ diameter with aspect ratio $\left(h_{o} / d_{o}\right)$ of 1.0. The distribution of hardness in the cold upset specimen was measured using the Brinell Hardness Tester. Also, this work discussing metallographic study of the upset specimens. The micrograph of samples is processed with the "Adobe Photoshop CS2" program and then applying the "Image $\mathrm{J}$ " program for estimating the average grain size. The upsetting operation was simulated using a commercial finite element code, ANSYS ver11.0. The results show that the finite element procedure is effective procedure to simulating cold upsetting process with maximum error $(7.7 \%)$.
\end{abstract}

Keywords Cold Upset, Fe of Copper Cylinder Under Cold Upset, Hardness and Grain Size Variation

\section{Introduction}

Forging is defined as a means of obtaining a desired shape by impact or the application of pressure to an object. Often times a material is preheated to decrease the required load necessary for deformation [1]. In forging metal is plastically deformed with application of pressure. Forging is used to change not only the shape but also the properties of the metal because it refines the grain size and therefore improves its structure [2]. During the forging deformation, the workpiece will often undergo recrystallization, thus developing a fine-grained microstructure and eliminating the cast dendritic structure that has inherently poor properties [3]. The main advantages of the forging process are high directional strength, structural integrity and uniformity, reduction in required machining, and material and weight savings (high strength to weight ratio) [4]. There are three basic types of forging are open die, closed die and impression forging. It is apparent that open die forging is less suitable for the production of complex finished shapes than closed die or impression forging [3]. Upsetting with a flat die has great significance in metal forming applications and is particularly useful when the geometrical shape of billets is very complicated [5]. Upsetting is defined as the axial compression of a metal in order to enlarge the cross-sectional area over either the whole or part of its length [6]. The research work aimed to attempting the simulation of the upset forging process of a cylinder using three dimensional finite elements model using ANSYS PROGRAM, elicitation of the relationship for the prediction of the grains size as the function of the percentage deformation and elicitation of the relationship between the hardness and the percentage deformation to predict the hardness distribution at the design stage itself, without performing experiments or with minimum experiments, one can monitor and control the cold forging process in the design stage itself. J. Schey, et al. 1982 [7] studied the effects of interface friction on pressure and deformation mode in compression at low aspect ratios, with the objective of providing useful practical methods for flow stress determination and for predictive calculations of upsetting forces. D. Yang, et al. 1991 [8] studied the determination of forging load and deformed bulge profile during upset forging of cylindrical billets using an upper-bound method. M. Sahin, et al. 2007[9] studied the effect of the surface roughness on the frictional properties for different materials and conditions. J. B. Rao, et al. 2009 [10] studied the deformation behavior of cast aluminium- $4 \%$ copper-2\% magnesium alloy in homogenized condition during upsetting at room temperature using a vision system. 
F. Soavl, et al. 1994[11] studied the non-uniform, cold deformation of an elastic, strain-hardening cylinder in axial compression between two rigid and two elastic dies with complete sticking to the die-workpiece interface using the finite element method. A. Jenner and B. Dodd 1981 [6] studied the maximum reduction in height obtainable in upsetting operations and dependence upon: the interfacial friction between the dies and workpiece, the geometry of the workpiece, the nature of the free surface and the ductility of the work material which is influenced by its prior deformation history. X. Hu and Z. Wang 2004 [12] studied the method of the multi-step upsetting of a flange to form a thick and wide flange on the end of the pipe. K. Baskaran, R. Narayanasamy 2008 [13] studied the effects of the initial aspect ratio on the work hardening behaviour during the cold upsetting under different stress state conditions. K. Baskaran and R. Narayanasamy 2008 [14] studied the bulging characteristics of preformed irregularly shaped pure aluminium billets (Elliptical billets) during cold upset forging using lubricant on both sides under different stress. K. Baskaran, R. Narayanasamy 2008 [5] studied the effect of various stress ratio parameters $\left(\sigma_{\theta} / \sigma_{\mathrm{z}}\right),\left(\sigma_{\mathrm{m}} / \sigma_{\mathrm{z}}\right),\left(\bar{\sigma} / \sigma_{\mathrm{z}}\right)$ and $\left(\sigma_{\mathrm{m}} / \bar{\sigma}\right)$ on cold upset forging of commercially pure aluminium solid billets and on the measured barrel radius namely major and minor axis and on the percentage height reduction.

\section{F. E. Formulation and Simulation of Cold Upset}

The Finite Element Analysis (FEA) is a powerful computational technique for approximate solutions to a variety of engineering problems having complex domains subjected to general boundary conditions. The basis of finite element analysis relies on the decomposition of the domain into a finite number of sub domains (elements) for which the systematic approximate solution is constructed by applying the variational or weighted residual methods. In this study, the application of commercial general finite element software - ANSYS - has been applied to model a forming operation. Models have been developed to simulate a basic forming operation (upsetting) that is applied in most of the cold forging parts sequences. The four approaches used for the derivation of the basic equations for the finite-element analysis. There are (1) the direct approach, (2) the variational method, (3) the method of weighted residuals, and (4) the energy balance approach [15]. The variational approach is based on one of two variational principles. It requires that among admissible velocities $u_{i}$ that satisfy the conditions of compatibility and incompressibility, as well as the velocity boundary conditions, the actual solution gives the following functional (function of functions) a stationary value: $\quad \pi=\int_{V} \bar{\sigma} \dot{\bar{\varepsilon}} d \mathrm{~V}-\int_{S_{F}} F_{i} u_{i} d S$, for rigid plastic materials

$$
\text { And } \quad \pi=\int_{V} E\left(\dot{\varepsilon}_{i j}\right) d V-\int_{S_{F}} F_{i} u_{i} d S \text {, for rigid - }
$$
viscoplastic materials (1), where $\bar{\sigma}$ is the effective stress, $\dot{\bar{\varepsilon}}$ is the effective strain-rate, $F_{i}$ represents surface tractions, and $E\left(\dot{\varepsilon}_{i j}\right)$ is the work function. The solution of the original boundary-value problem is then obtained from the solution of the dual variational problem, where the first-order variation of the functional vanishes, namely, $\delta \pi=$ $\int_{V} \bar{\sigma} \delta \dot{\bar{\varepsilon}} d \mathrm{~V}-\int_{S_{F}} F_{i} \delta u_{i} d S=0$ (2), where $\bar{\sigma}=\bar{\sigma}(\bar{\varepsilon})$ and $\bar{\sigma}=\bar{\sigma}(\bar{\varepsilon}, \dot{\bar{\varepsilon}})$ for rigid-plastic and rigid viscoplastic materials, respectively. The incompressibility constraint on admissible velocity fields in eq. (1) may be removed by introducing a Lagrange multipilier $\lambda[23,24]$ and modifying the functional (3.2) by adding the term $\int \lambda \dot{\varepsilon}_{v} d V$, where $\dot{\varepsilon}_{v}=\dot{\varepsilon}_{i i}$, is the volumetric strain-rate. Then, $\delta \pi=\int_{V} \overline{\sigma \delta} \dot{\bar{\varepsilon}} d \mathrm{~V}+$ $\int_{V} \lambda \delta \dot{\varepsilon}_{v} d V+\int_{V} \dot{\varepsilon}_{v} \delta \lambda d V-\int_{S_{F}} F_{i} \delta u_{i} d S=0$ (3).

Another way of removing the constraint is to use the penalized form of the incompressibility as $\delta \pi=$ $\int_{V} \bar{\sigma} \overline{\bar{\varepsilon}} d \mathrm{~V}+K \int_{V} \dot{\varepsilon}_{v} \delta \dot{\varepsilon}_{v} d \mathrm{~V}-\int_{S_{F}} F_{i} \delta u_{i} d S=0$ (4), where $K$, a penalty constant, is a very large positive constant. In eq. (3) and (4), $\delta u_{i}$ and $\delta \lambda$ are arbitrary variations and $\delta \dot{\bar{\varepsilon}}$ and $\delta \dot{\varepsilon}_{v}$ are the variations in strain-rate derived from $\delta u_{i}$. Equation (3) or (4) is the basic equation for the finite-element formulation [15].

The ANSYS program is capable of simulating problems in a wide range of engineering disciplines such as structural analysis, thermal analysis and fluid analysis. The analysis of forging process and determination of stresses and strains requires utilizing the structural analysis. Non-linear models consist of stressing the material past its elastic capabilities [16].Two solution methods are available for solving structural problems in the ANSYS program that is the $\mathrm{h}$-method and $\mathrm{p}$-method .Although, the h-method requires a fine mesh than p-method, the h-method will be used to the analysis of test specimens because it can be used for linear and non-linear analysis but p-method can be used for linear structural static analysis only [17].

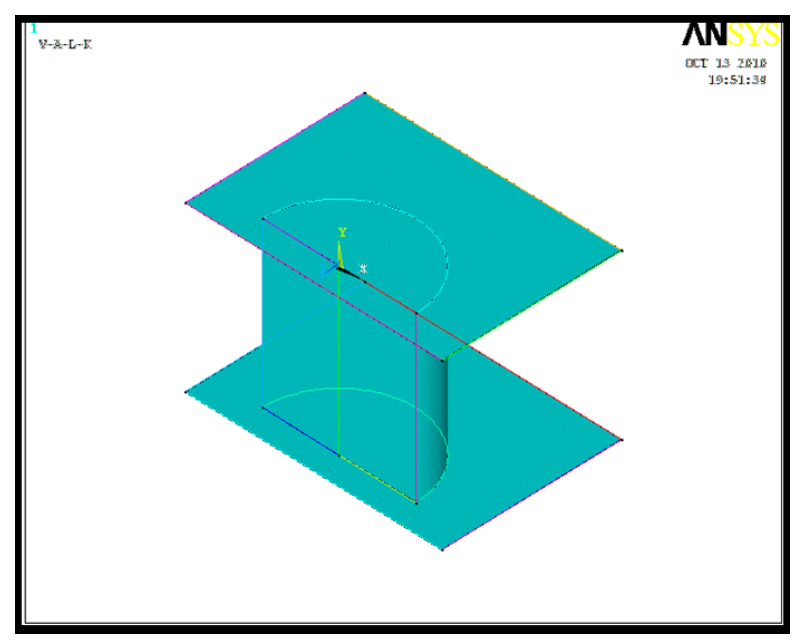

Figure 1. The half model for specimen.

Finite element analysis of deformation behavior of cold upsetting process of cylindrical specimen was carried out for the given frictional condition " $\mathrm{m} "$ equal to 0.36 . The geometry of the specimen has prepared according to 
experimental work where cylindrical specimens of $30 \mathrm{~mm}$ diameter with aspect ratio $\left(\mathrm{h}_{\mathrm{o}} / \mathrm{d}_{\mathrm{o}}\right)$ of 1.0 using in this analysis. The analysis can also be extended to non-axisymmetric problems using half portion of 3D model as shown in Fig. (1) was considered with symmetric boundary conditions.

Material models were selected based on the properties of the tooling and billet materials. Due to high structural rigidity of the tooling, only the following elastic properties of tooling (steel) were assigned assuming the material to be isotropic. Young's modulus $\mathrm{E}=210 \mathrm{GPa}$ and Poisson's ratio $=0.30$ [27]. For billet material (pure copper) model selected is isotropic Mises plasticity with $\mathrm{E}=110 \mathrm{GPa}$ and Poisson's ratio $=0.343$ and plastic properties defined by entering tangent modulus and yield strength that were about $100 \mathrm{GPa}$ and 60MPa respectively [18].

For such analysis, rigid tools need not be meshed. The billet geometry was meshed with 10-node tetrahedral elements (solid 92 in ANSYS Library). SOLID92 has a quadratic displacement behavior and is well suited to model irregular meshes. The element is defined by ten nodes having three degrees of freedom at each node: translations in the nodal $\mathrm{x}, \mathrm{y}$, and $\mathrm{z}$ directions. The element also has plasticity, creep, swelling, stress stiffening, large deflection, and large strain capabilities [19]. The geometry, node locations, and the coordinate system for this element are shown in Fig. (2). The 3-D finite elements mesh for half model of this specimen is shown in Fig. (3).

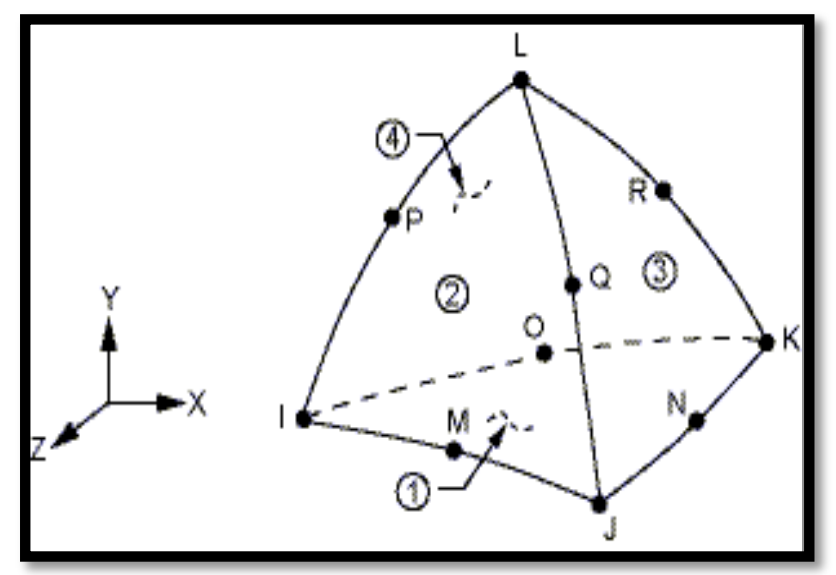

Figure 2. The geometry, node locations, and the coordinate system for SOLID92 element.

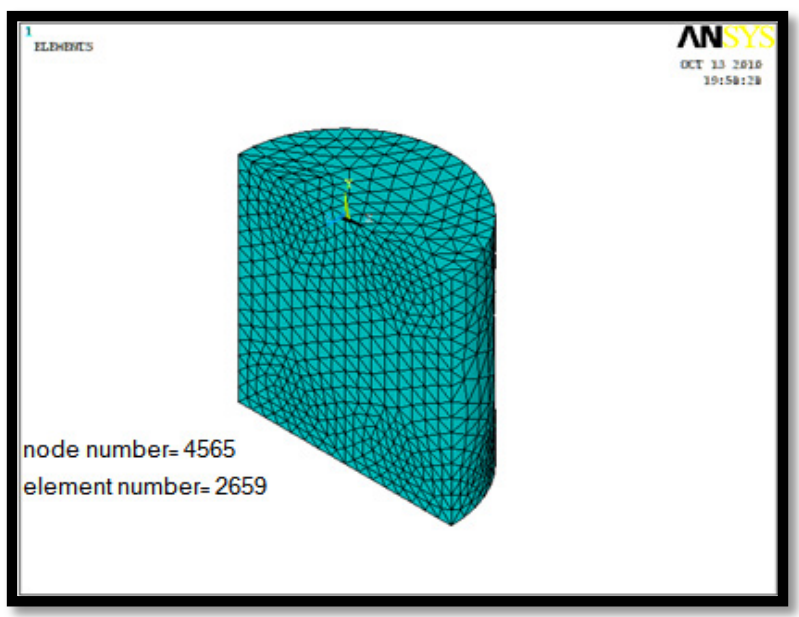

Figure 3. 3-D finite elements mesh.

Element size was selected on the basis of convergence criteria and computational time. Too coarse a mesh may never converge and too fine a mesh requires long computational time without much improvement in accuracy. The tetrahedral elements can easily be accommodated in any shape. This reduces the number of iterations and steps to be solved.

Rigid-flexible contact analysis was performed for the forming process. A 3D, 8-noded, higher-order quadrilateral element CONTA 174 (of ANSYS library) that can be located on the 3D solid or shell elements with mid side nodes is used. It can be degenerated to 3-7 node quadrilateral/triangular shapes. The contact elements themselves overlay the solid elements describing the boundary of a deformable body that is potentially in contact with the rigid target surface, defined by TARGE 170 . Hence a target is simply a geometric entity in space that senses and responds when one or more contact elements move into a target segment element.

CONTA174 is used to represent contact and sliding between 3-D "target" surfaces (TARGE170) and a deformable surface, defined by this element. The element is applicable to 3-D structural and coupled field contact analyses. This element is located on the surfaces of 3-D solid or shell elements with mid side nodes. Contact occurs when the element surface penetrates one of the target segment elements (TARGE170) on a specified target surface [19].

Coulomb and shear stress friction is allowed. This element also allows separation of bonded contact to simulate interface delamination. The geometry and node locations are shown in Fig. (4). The element is defined by eight nodes (the underlying solid or shell element has midside nodes). It can degenerate to a six node element depending on the shape of the underlying solid or shell elements. If the underlying solid or shell elements do not have midside nodes [19]. 


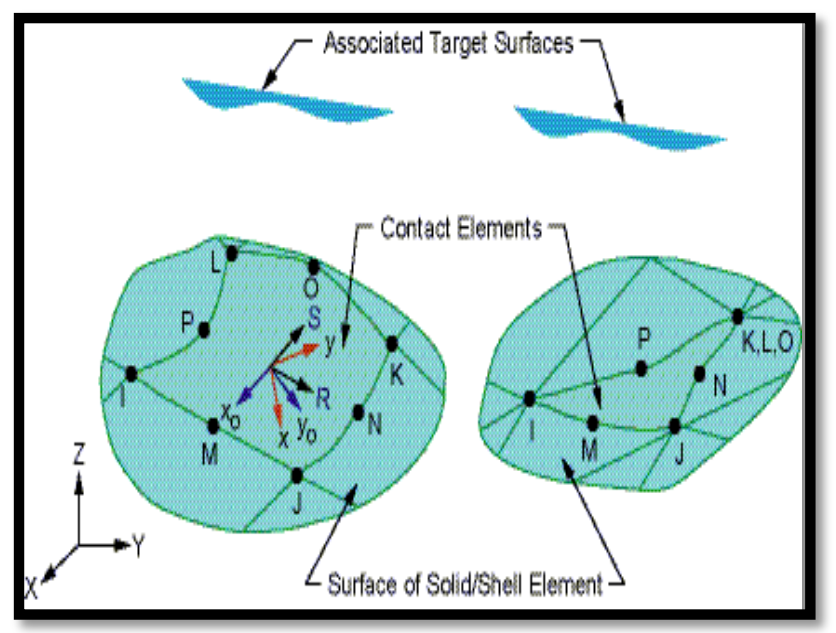

Figure 4. The geometry and node locations for CONTA174.

TARGE170 is used to represent various 3-D "target" surfaces for the associated contact elements (CONTA173, CONTA174, CONTA175, CONTA176, and CONTA177). The contact elements themselves overlay the solid, shell, or line elements describing the boundary of a deformable body and are potentially in contact with the target surface, defined by TARGE170. The geometry and node locations are shown in Fig. (5).

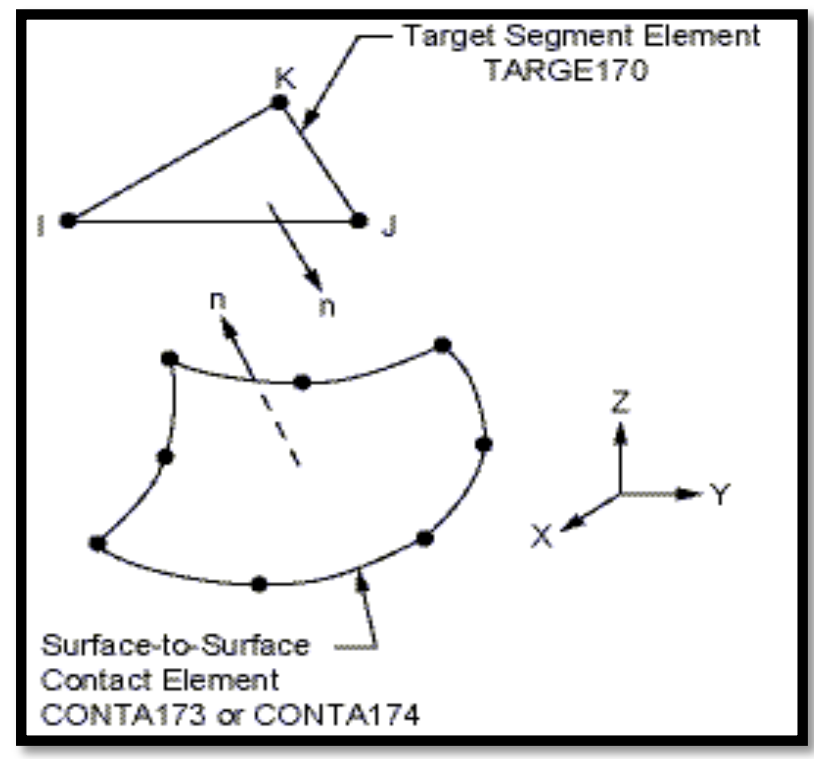

Figure 5. The geometry, node locations, and the coordinate system for TARGE170.

This target surface is discretized by a set of target segment elements (TARGE170) and is paired with its associated contact surface via a shared real constant set. You can impose any translational or rotational displacement, temperature, voltage, and magnetic potential on the target segment element. You can also impose forces and moments on target elements.

For rigid target surfaces, these elements can easily model complex target shapes. For flexible targets, these elements will overlay the solid, shell, or line elements describing the boundary of the deformable target body [19].
Each target surface can be associated with only one contact surface, and vice-versa. However, several contact elements could make up the contact surface and thus come in contact with the same target surface. Likewise, several target elements could make up the target surface and thus come in contact with the same contact surface. For either the target or contact surfaces, you can put many elements in a single target or contact surface, but doing so may increase computational cost. For a more efficient model, localize the contact and target surfaces by splitting the large surfaces into smaller target and contact surfaces, each of which contain fewer elements [19].

After completing the material model and making of mesh elements for this specimen, the boundary condition will be applied as shown in Fig. (6) which includes loads which taking from experimental work for each deformation stage (162.77MPa, $184 \mathrm{MPa}, 249.116 \mathrm{MPa}, 332.626 \mathrm{MPa}$, and $368 \mathrm{MPa})$ for deformation percentages $(13 \%, 17 \%, 32.4 \%$, $41 \%, 50 \%$ ) respectively. Analysis type doing using large displacement static and the automatic time stepping is on. In the current work, Bilinear isotropic hardening i.e. The Bilinear Isotropic Hardening (BISO) option uses the von Mises yield criteria coupled with an isotropic work hardening assumption. This option is often preferred for large strain analyses. You can combine BISO with Chaboche, creep, viscoplastic, and Hill anisotropy options to simulate more complex material behaviors.

The program will continue to perform equilibrium iterations until the convergence criteria are satisfied.

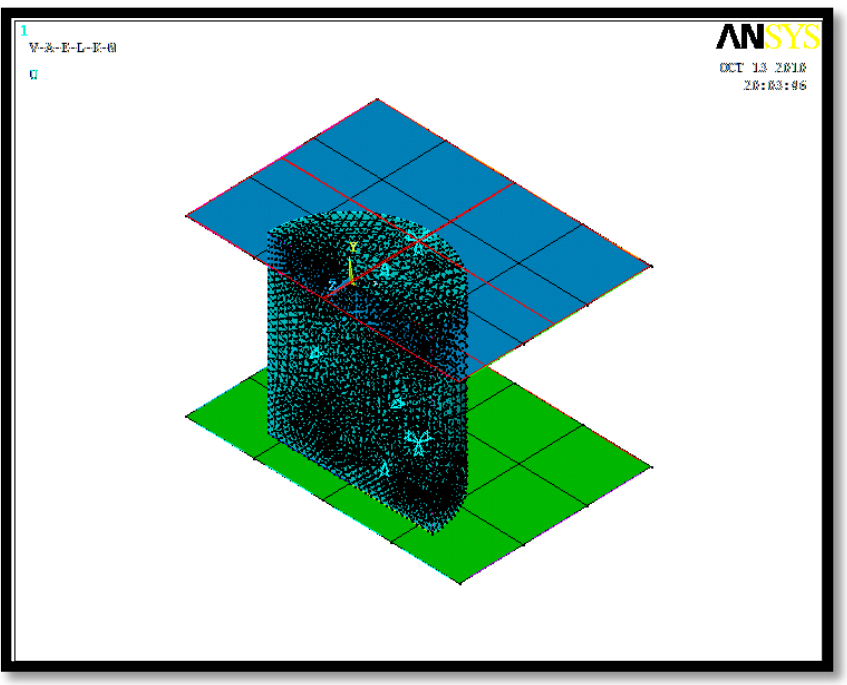

Figure 6. The application of B.C..

The FE simulations were conducted for different strain levels (different deformation percentages) for given friction factor $(m)$. Effective strain values were measured for certain points from the surface center to periphery for the distance $2 \mathrm{~mm}$ between each point and ether on the top compressive surface of the upset specimen. The effective strains were obtained at this point by path operation invaluable in ANSSYS program.

During upset forging of complex parts, the stress and 
strain at each point during deformation is of a complex nature, unlike in uniaxial tensile testing. The total strain at any point of the deforming sample involves an elastic and plastic part, i.e., $\varepsilon_{i j}=\varepsilon_{i j}(\mathrm{e})+\varepsilon_{i j}(p)$

Since the elastic strains are very small, when compared to that of large plastic strains during forging, the total strain can be approximated to plastic strains only and hence, $\varepsilon_{i j} \approx$ $\varepsilon_{i j}(p) \quad[20]$.

The 3-D nature of plastic strain during forging can be represented by a single quantity "Effective strain $=\bar{\varepsilon}$ " which is a function of plastic strains in normal and shear directions. The effective strain can be obtained by equating the plastic work done in 1-D to the plastic work done in the general state, i.e., $\bar{\sigma} d \bar{\varepsilon}=\sigma_{1} d \varepsilon_{1}+\sigma_{2} d \varepsilon_{2}+\sigma_{3} d \varepsilon_{3}$. So, the plastic strain increment can be written as, $d \bar{\varepsilon}=1 / \bar{\sigma}\left(\sigma_{1} d \varepsilon_{1}+\sigma_{2} d \varepsilon_{2}+\right.$ $\left.\sigma_{3} d \varepsilon_{3}\right)$.

Now, by following von Mises plasticity theory, and normality condition, one can find the strain increments, viz., $d \varepsilon_{1}, d \varepsilon_{2}, d \varepsilon_{3}$. From this, the plastic strain increment can be obtained as [20], $d \bar{\varepsilon}=\left[2 / 3\left(d \varepsilon_{1}^{2}+d \varepsilon_{2}^{2}+d \varepsilon_{3}^{2}\right)\right]^{1 / 2}$. Representing in general coordinate system, $d \bar{\varepsilon}$ $=\quad\left[2 / 3\left(d \varepsilon_{11}^{2}+d \varepsilon_{22}^{2}+d \varepsilon_{33}^{2}+2 d \varepsilon_{12}^{2}+2 d \varepsilon_{13}^{2}+\right.\right.$ $\left.\left.2 d \varepsilon_{23}^{2}\right)\right]^{1 / 2}$. Finally in terms of total plastic strains, Effective strain, $\bar{\varepsilon}=\left[2 / 3\left(\varepsilon_{r}^{2}+\varepsilon_{\theta}^{2}+\varepsilon_{z}^{2}\right)\right]^{1 / 2}$.

\section{Experimental Work}

\subsection{Chemical Composition}

Commercial pure copper in wrought form was procured from local market of $1000 \mathrm{~mm}$ length, $35 \mathrm{~mm}$ diameter. The chemical composition ( $\mathrm{wt} \%$ ) of the tube which is performed by chemical analysis instrument in the Najibia power station-Basrah was found as follow: $(98.72 \% \mathrm{Cu}-0.01 \% \mathrm{Zn}$ $0.15 \% \mathrm{~Pb}-0.09 \% \mathrm{Fe}-0.02 \% \mathrm{Sn}-1.01 \%$ other elements).

\subsection{Ring Compression Test}

Ring compression tests were conducted to determine the friction factor ' $m$ '. Standard ring compression samples of outside diameter: inside diameter: height $=6: 3: 2(24: 12: 8$ $\mathrm{mm}$ ) [18] as shown in Fig. (7) were deformed slowly. Specimens of standard dimensions were prepared using conventional machining operations of turning, facing, drilling and boring. The compression tests were conducted using a universal testing machine (tensile test machine) with capacity of $(10,40,100)$ tons at room temperature as shown in Fig. (8). Five rings deformed to different strain levels (different deformation percentages) as shown in Fig. (9).

After compression test, the final inner diameters and final height of rings were measured using a digital vernier caliper.
The percentage change in inner diameter is measured for every known reduction in sample thickness or height. The decrease in internal diameter of the ring compression test was plotted against the deformation on Male and Cockcroft [18] calibration curves in increments approximately of $10 \%$ deformation as shown in Fig. (10). When these ring compression values were fit into calibration curves for the given set of dies, it was found that the friction factor " $\mathrm{m}$ " was equal to 0.36 . The same set of dies was used for upset tests also.

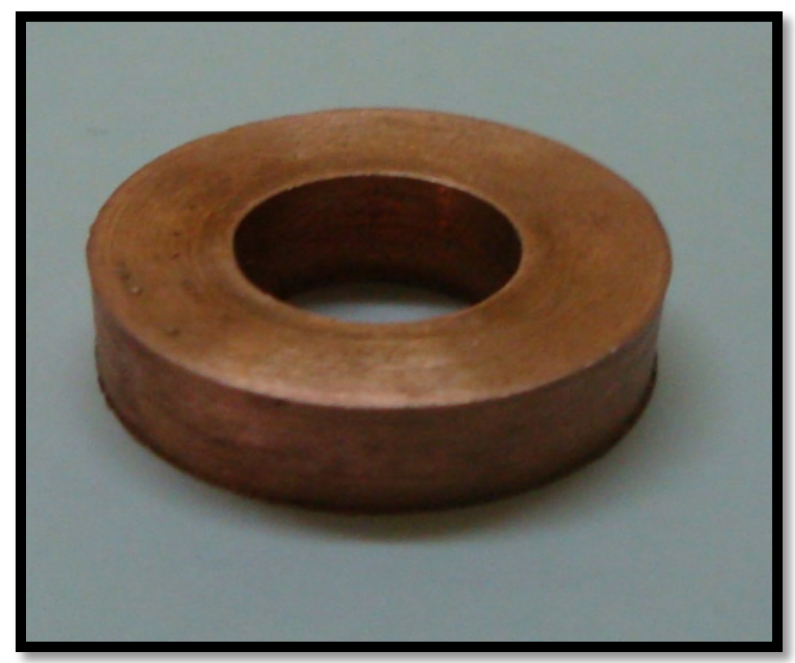

Figure 7. The ring compression test specimen.

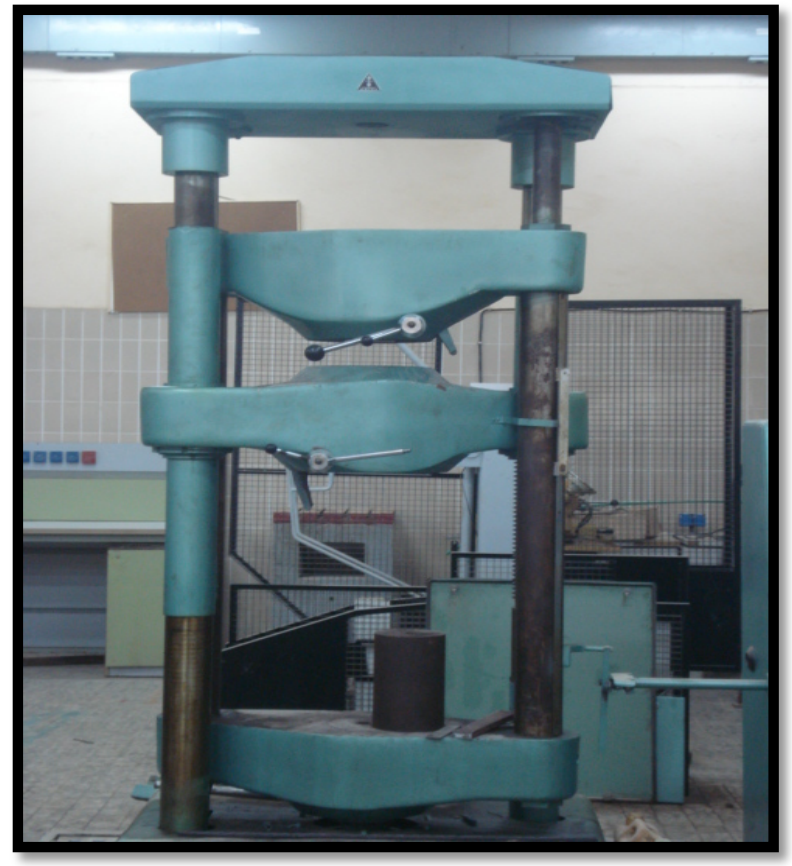

Figure 8. Testing machine. 


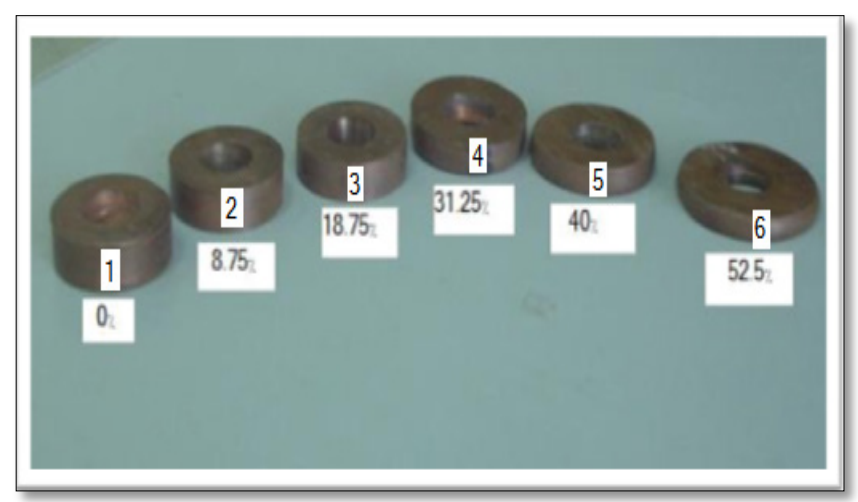

Figure 9. Copper rings deformed.

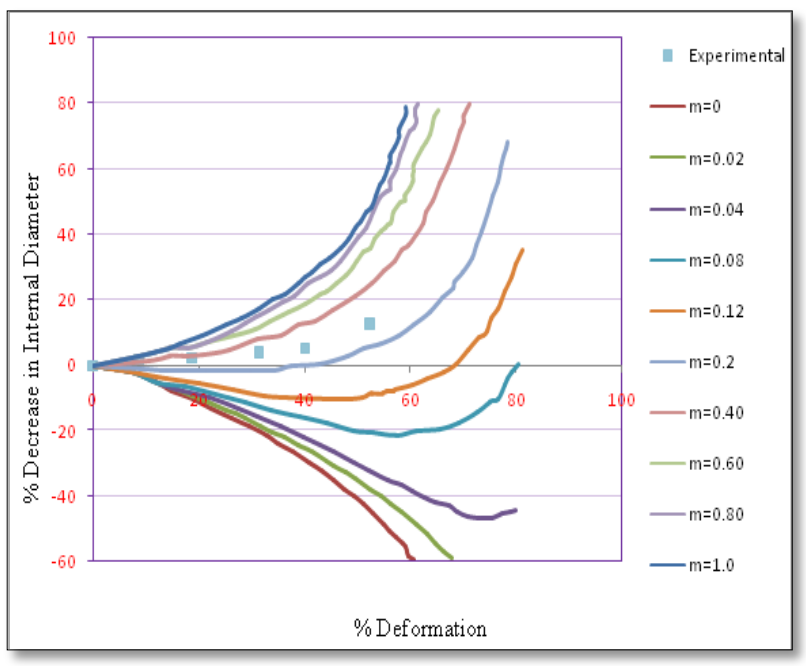

Figure 10. Ring test calibration curves.

\subsection{Cold Upsetting of a Cylinder}

Cylindrical specimens of $30 \mathrm{~mm}$ diameter with aspect ratio $\left(\mathrm{h}_{\mathrm{o}} / \mathrm{d}_{\mathrm{o}}\right)$ of 1.0 as shown in Fig. (11) were prepared using conventional machining operations of turning, facing. The upset-forging tests were conducted using a universal testing machine at room temperature. Five specimens deformed to different strain levels (different deformation percentages) as shown in Fig. (12).

\subsection{Hardness Test}

Metal forming operations involve a complex interaction of the metal and the dies and equipment used to deform it. Hardness is the direct measure of resistance given by the material to plastic deformation and hence is a better candidate to measure the deformation behavior of any cold forged product [20]. The distribution of hardness in the cold upset specimen was measured using the Brinell Hardness Tester. The hardness $(\mathrm{BHN})$ values were obtained at the same locations where the effective strains were obtained from ANSYS program. Hardness values were measured for certain points from the surface center to periphery for the distance $2 \mathrm{~mm}$ between each point and ether on the top compressive surface of the upset specimen as shown in Fig.
(13). Also hardness measurements were performed for ten randomly points on the top compressive surface for calculate surface average hardness.

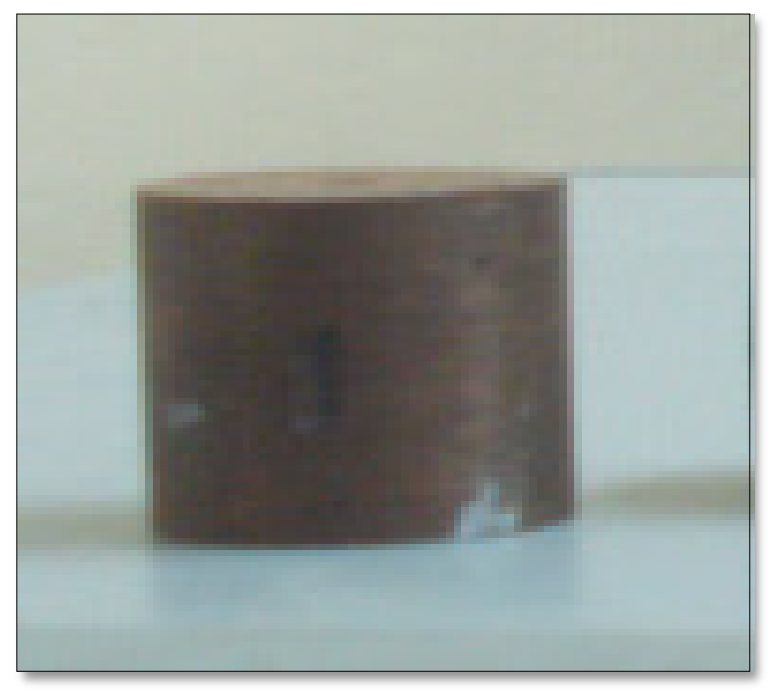

Figure 11. Cylindrical specimen.

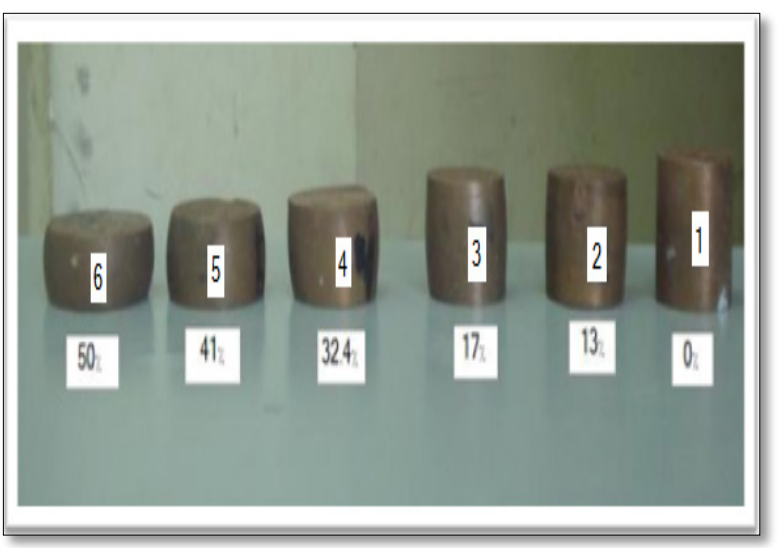

Figure 12. copper specimens deformed.

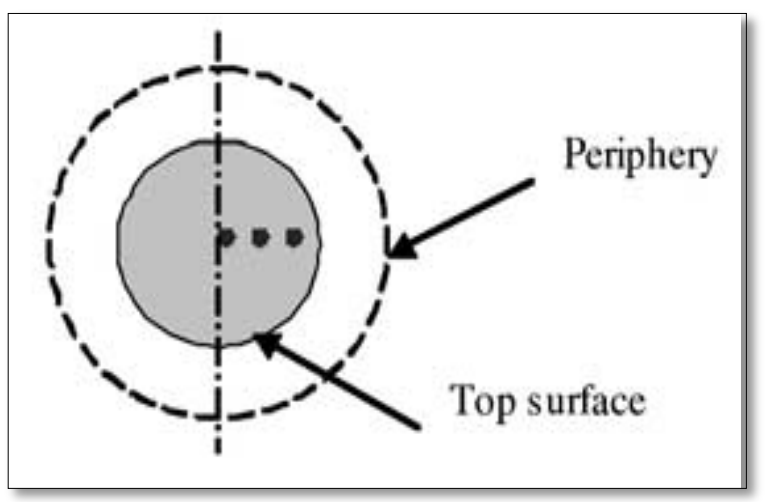

Figure 13. Points from the surface center to periphery.

\subsection{Metallographic Study}

After prepare samples for this study by mounting, wet grinding, polishing and etching, the imaging of microstructure was done by using an optical microscope 
connected to computer. Then, the micrograph of samples is processed with the "Adobe Photoshop CS2" program and then by applying the "Image J" program for estimating the average grain size.

\section{Results and Discussion}

\subsection{Effect of Deformation Percentage on the Average Surface Hardness}

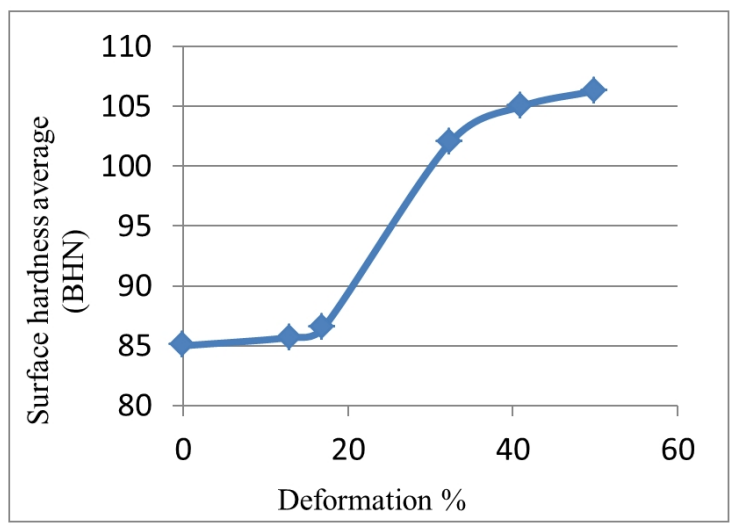

Figure 14. Variation of surface hardness average with deformation percentage.

The variation of hardness (BHN) on the top compressive surface of the cold upset cylinder (average surface hardness) with deformation percentage is presented in Fig. (14). It was found that average surface hardness increase with increasing deformation percentage. In general, when metal are deformed at room temperature, the deformation is accommodated by layers of atoms sliding over one another with the crystal grains of metal. As this sliding occurs, the metal grains become distorted, the atom layers buckle, and there is a rapid increase of small regions of atomic misfit ( known as dislocations ) within the grains. Because of the distortion and increase in dislocation content, further deformation becomes more difficult; in the other words, the metal becomes harder and its strength rises whilst the ductility drops. This increase in hardness of metals when they are deformed is a very important property and is known as work hardening.

\subsection{Variation of Hardness on the Flat Surface (or Interface)}

The variation of hardness (BHN) from the center to the periphery on the top compressive surface of the cold upset cylinder for each deformation percentage is shown in Fig. (15). The figure shows that for a single curve, the hardness increase from the center to the periphery. The regions present on the periphery suffer much defect (dislocations) movement with compare to center region which is more adhering. This illustrates hardness increasing albeit with low percentage on the periphery regions compare with the center. Also this figure shows that as deformation percentage increasing, hardness increase and this attributed to strain hardening.

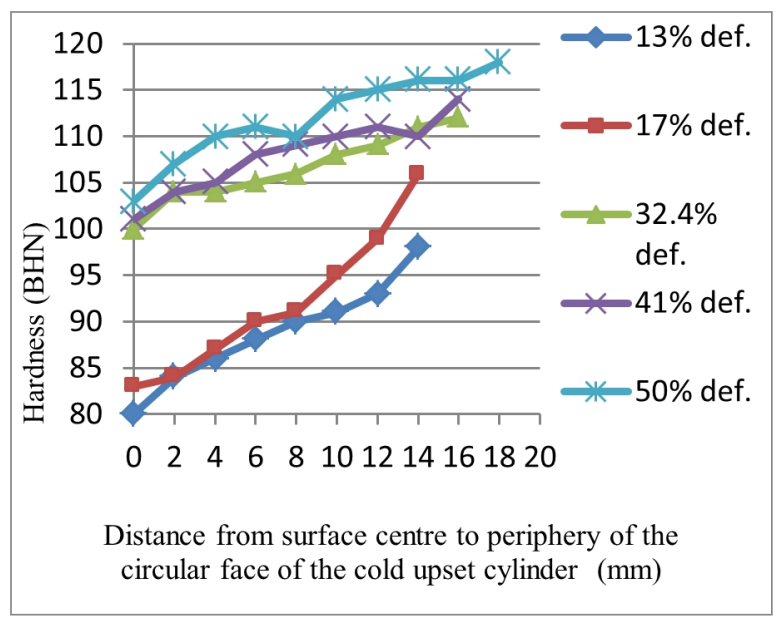

Figure 15. Variation of hardness (BHN) from the center of the circular face to the outer surface of the cold upset cylinder.

\subsection{Effect of Deformation Percentage on the Grain Size}

Fig. (16) show change in average grain size in each deformation percentage. Figure shows that as deformation percentage increasing, the average grain size decreasing. Severe plastic deformation is one of the methods of obtaining very fine crystalline structure in different bulk metals and alloys. Severe plastic deformation causes the formation of micrometer and sub-micrometer sized subgrains in the initially coarse grain materials. As a result of that enhanced mechanical performance is observed. The mechanism responsible for this effect is still under investigation, however, it is believed that short and long-range intersecting shear bands produced by plastic deformation play a major role at grain subdivision and local dynamic recovery and recrystallization processes contribute to grain refinement. The fine grained structure of materials obtained by severe plastic deformation leads to super plastic behaviour of these materials at low temperatures [21].

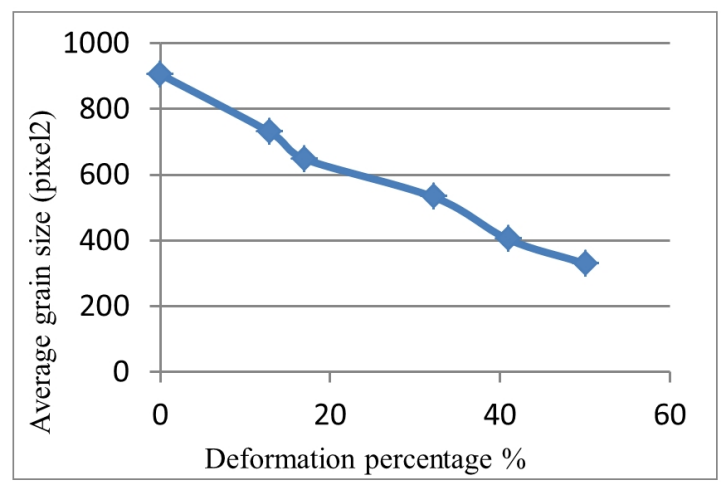

Figure 16. Effect deformation percentage on the average grain size.

\subsection{Effect of Average Grain Size on the Average Surface Hardness}

Fig. (17) shows effect average grain size on the average 
surface hardness. As the deformation percentage increases i.e. the average grain size decreasing, the average surface hardness increasing as a result deformation percentage increasing. With decreasing average grain size, increasing grain boundaries and this increase of the obstructions of the defect movement lead to increase of the hardness. The fact that strength (hardness) of material increases with decreasing grain size in its structure was known from the early fifties of the last century, when famous Hall-Petch relationship was formulated $\mathrm{Re}=\sigma_{\circ}+\mathrm{k} \cdot d^{-1 / 2}$, where $\mathrm{Re}$ is yield value, $\sigma_{\circ}$ is the stress necessary for overcoming of Peierls-Nabarr friction stress, resistance of dissolved foreign atoms, resistance of precipitates from solid solution and lattice defects, $k$ is the constant, the measure of which is the value of shearing stress necessary for release of accumulated dislocations, $d$ is the grain size [23].

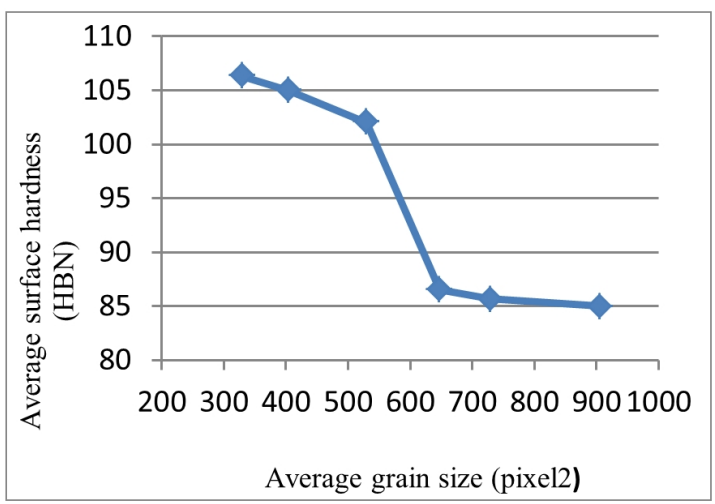

Figure 17. Effect average grain size on the average surface hardness.

The Hall-Petch effect in grain refinement materials is attributed to the grain boundaries acting as efficient obstacles to dislocations. Consequently, a dislocation pile-up can be formed against a grain boundary inside a grain [22].
The main aim of the ANSYS analysis is that to find the variation of effective strain from the center to the periphery on the top compressive surface of the cold upset cylinder for each deformation percentage, see Fig. (18). This figure shows that the relationship between the distance and the effective strain is linear.

The slope of the line increased with increasing the deformation percentage i.e. at the low percent (13\%) a small variation in the effective strain from the center to the periphery $($ slope $=0$ ) while at high deformation percent $(50 \%)$ the variation increased (slope $=0.003)$.

The increasing in the effective strain from the center to the periphery of the cylinder is because of the material in inner region (at the center of the cylinder), deforms in adhere form while at the periphery the metal can be deform severely and hence undergoes (a) differential straining resulting in an increase effective strain, and (b) differential strain hardening resulting in an increase hardness.

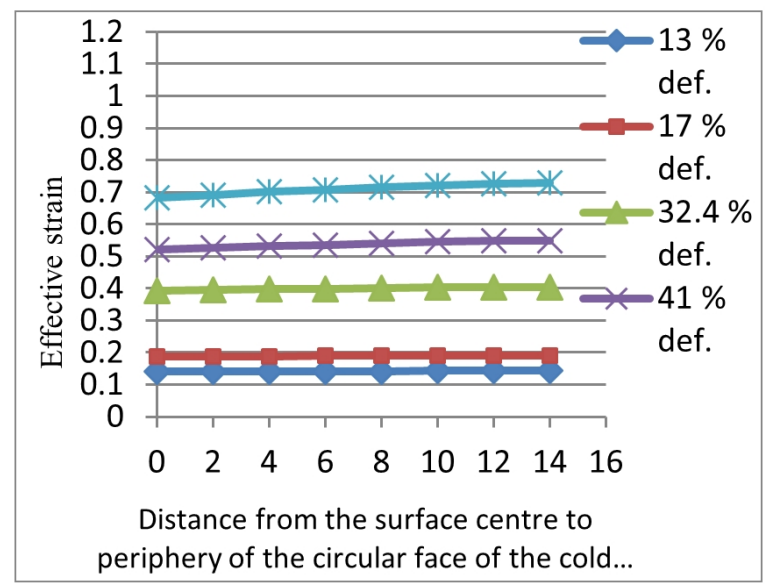

Figure 18. Variation of effective strain from the center of the circular face to the outer surface of the cold upset cylinder.

\subsection{Variation of the Effective Strain on the Flat Surface}

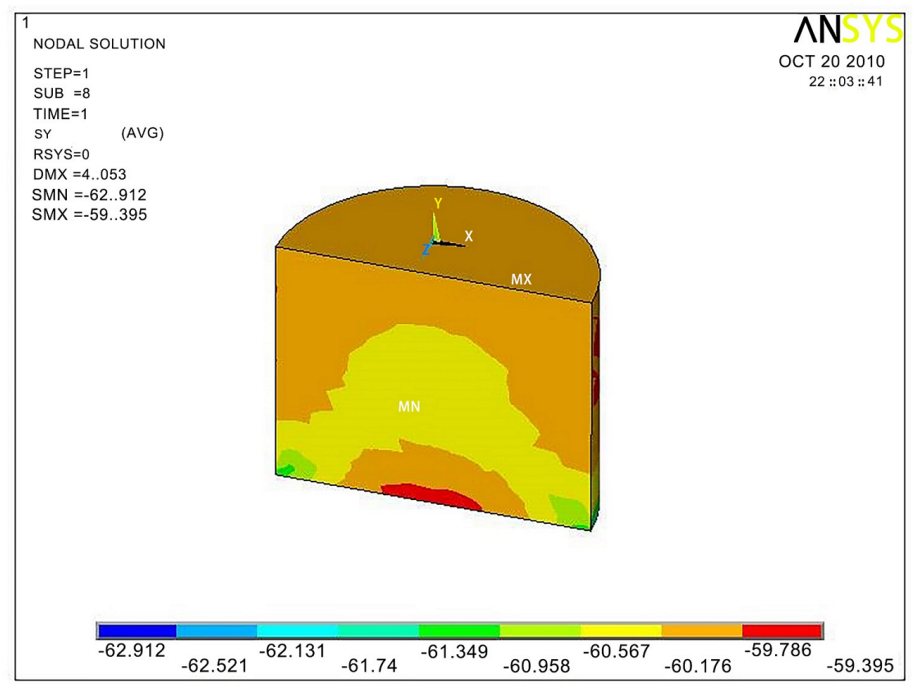




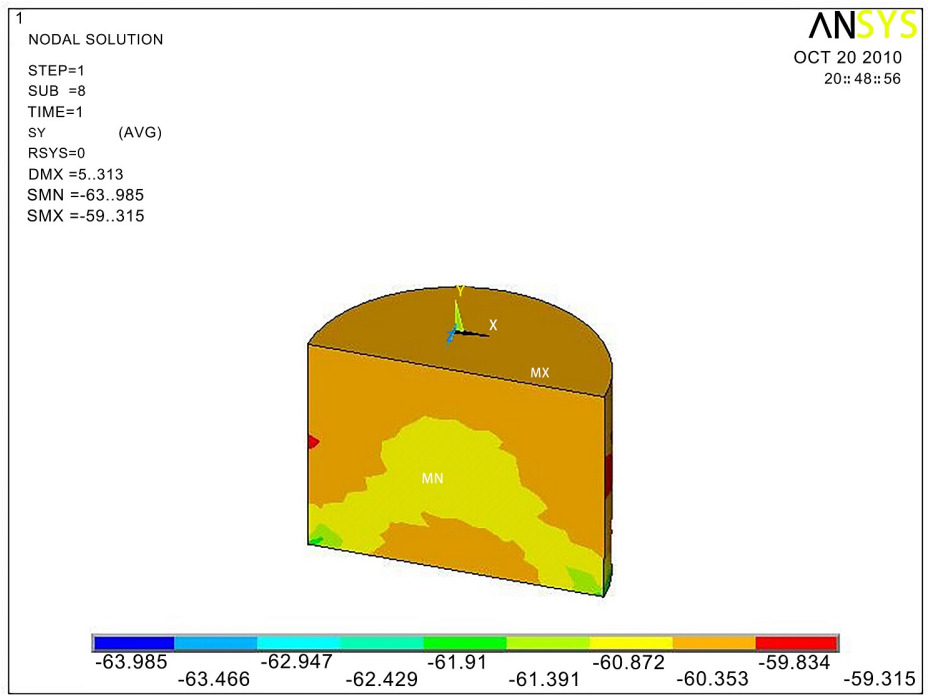

(b)

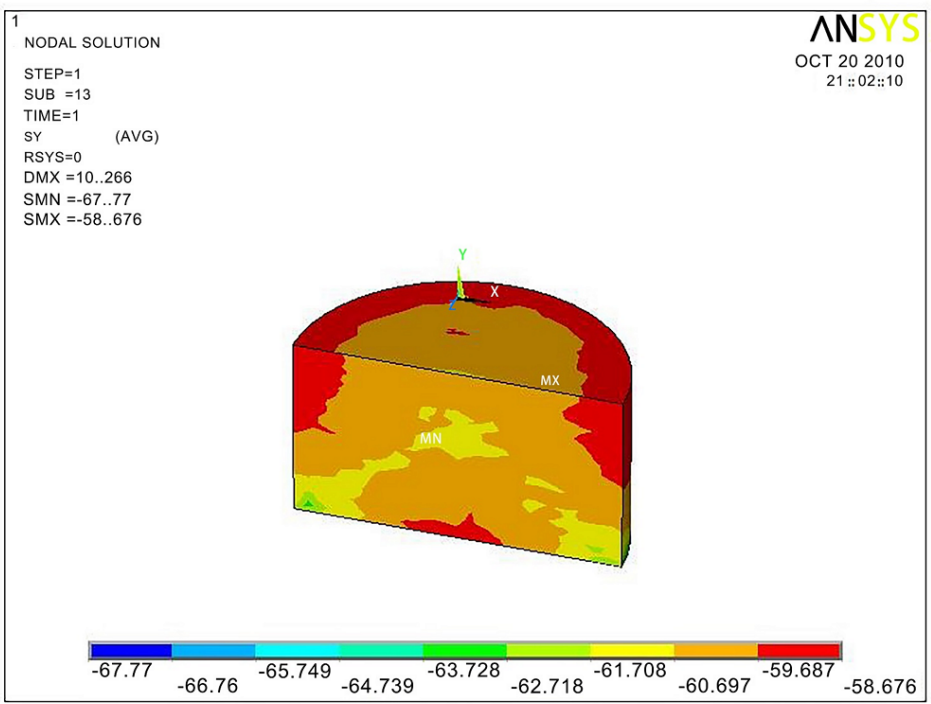

(c)

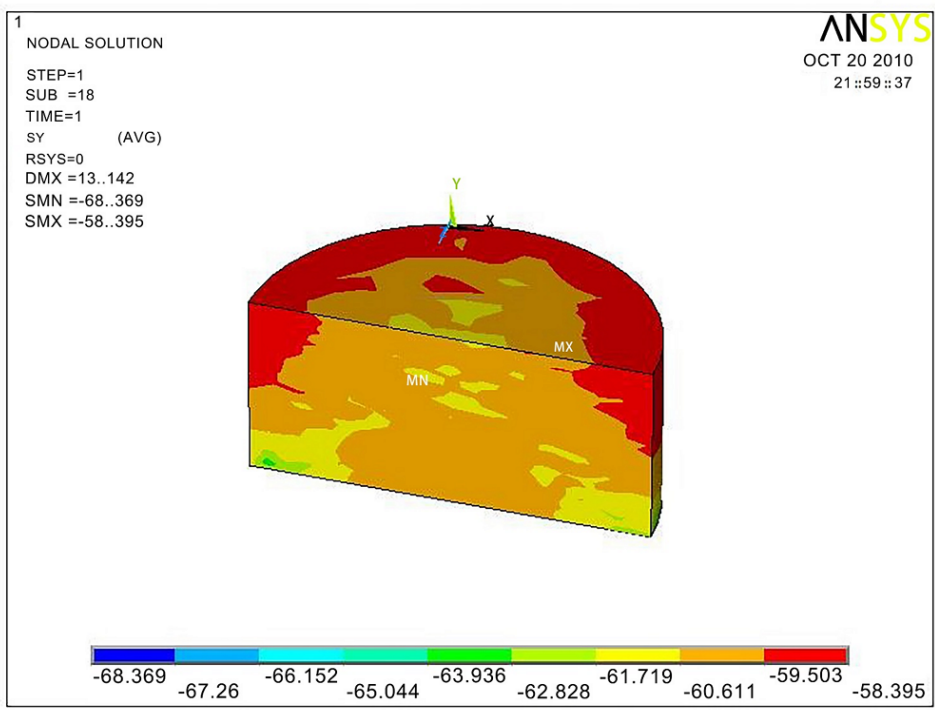

(d) 


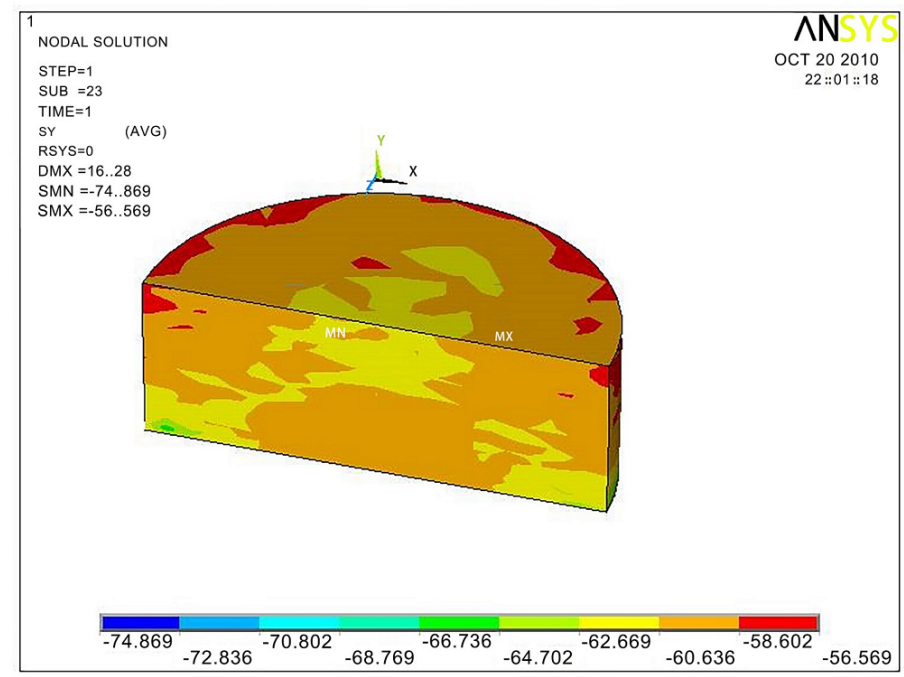

(e)

Figure 19. Stresses distribution of half ANSYS model of cylinder specimen: (a) $13 \%$ deformed, (b) $17 \%$ deformed, (c) $32.4 \%$ deformed, (d) $41 \%$ deformed, and (e) $50 \%$ deformed.

Fig. (19) shows a 3D contour plot of stress distribution in the y direction (deformation direction) of cold upset cylinder at different deformation percentages.

Fig. (20) shows a 3D contour plot of strain distribution in the y direction (deformation direction) of cold upset cylinder at different deformation percentages.

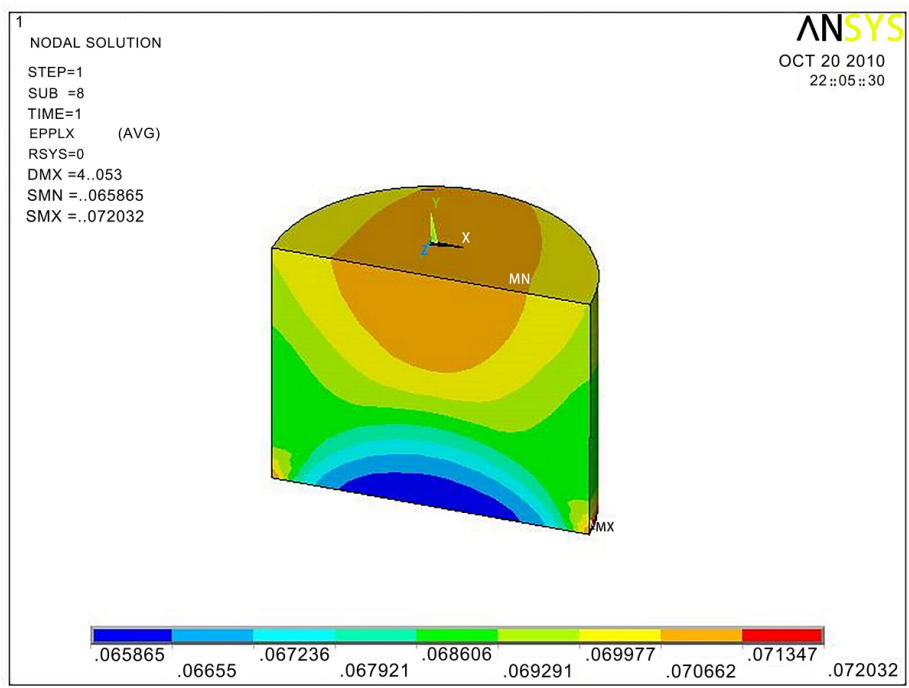

(a) 


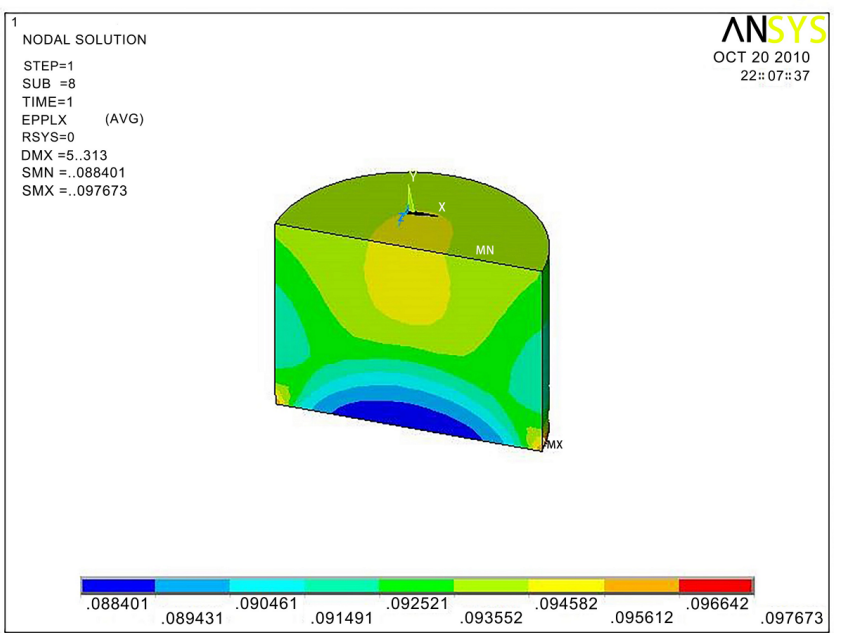

(b)

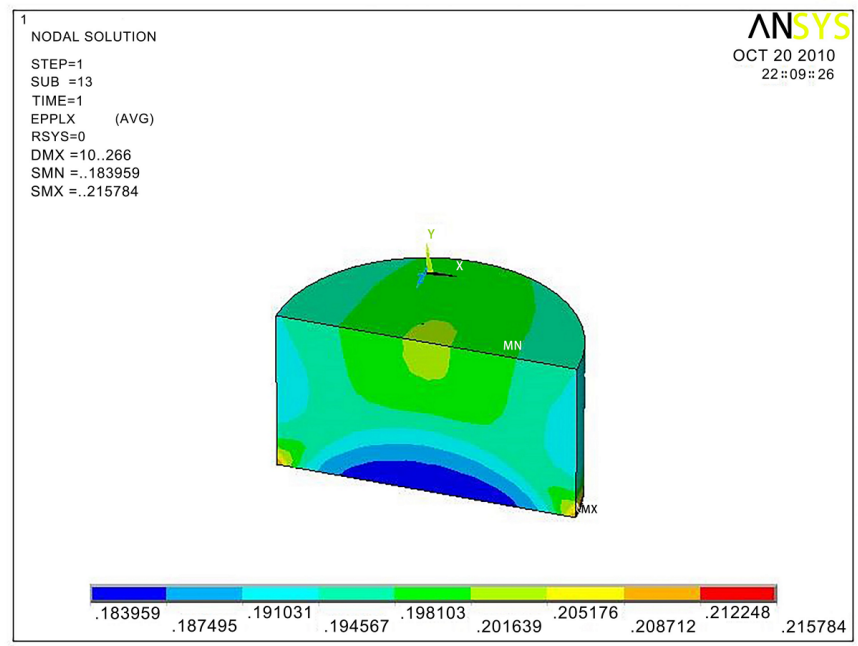

(c)

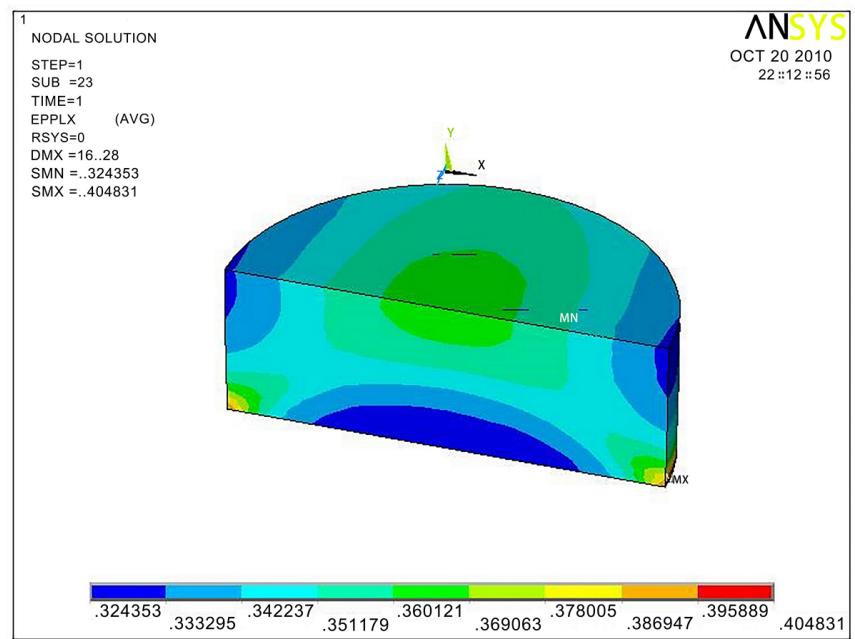




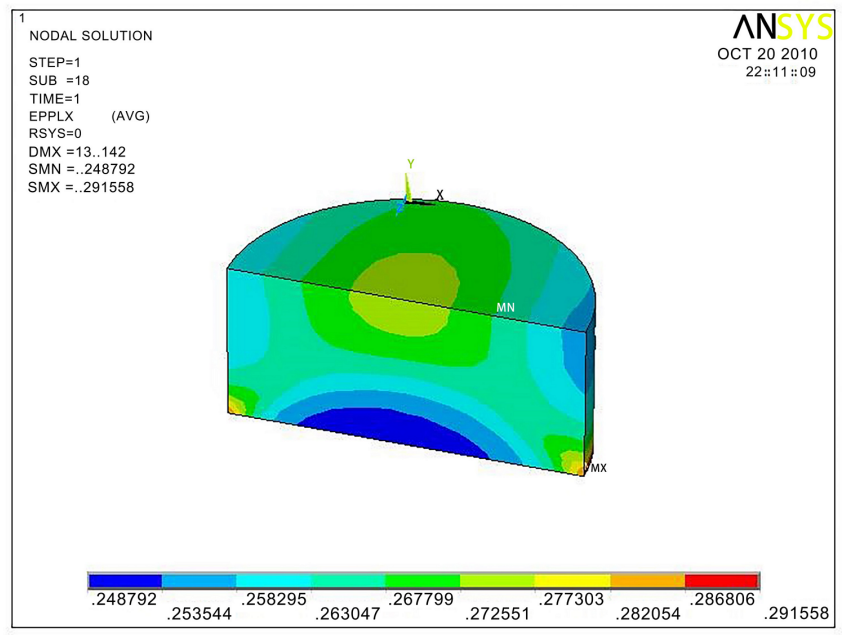

(e)

Figure 20. strain distribution of cylinder specimen: (a) $13 \%$ deformed, (b) $17 \%$ deformed, (c) $32.4 \%$ deformed, (d) $41 \%$ deformed, and (e) $50 \%$ deformed.

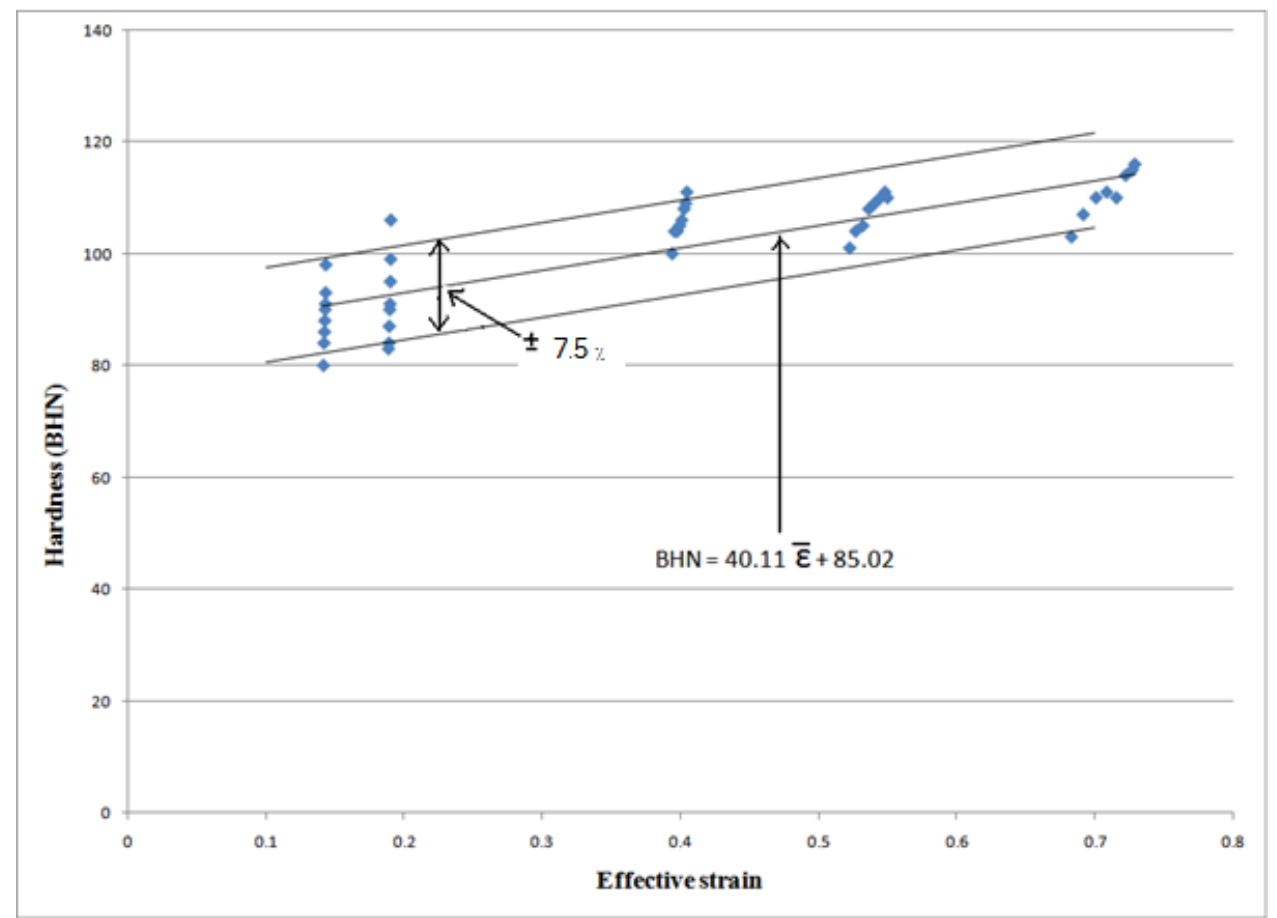

Figure 21. Variation of hardness (BHN) with effective strain $(\bar{\varepsilon})$.

\subsection{Effect of Effective Strain on Hardness}

It is possible to predict the hardness distribution at the design stage itself, without performing experiments or with minimum experiments, one can monitor and control the cold forging process in the design stage itself. Fig. (21) shows the scatter diagram of hardness (BHN) to effective strain $(\bar{\varepsilon})$. All the experimental hardness (BHN) values were plotted with the effective strain $(\vec{\varepsilon})$ values from ANSYS simulations for all deformation percentages.

The scatter diagram indicates a linear variation between the effective strain $(\vec{\varepsilon})$ and hardness $(\mathrm{BHN})$. Therefore, a straight line fit was developed for hardness (BHN) as a function of effective strain $(\bar{\varepsilon})$. The empirical relationship established between hardness (BHN) and effective strain $(\vec{\varepsilon})$ is, $\mathbf{B H N}=\mathbf{4 0 . 1 1}(\bar{\varepsilon})+\mathbf{8 5 . 0 2}$.

This empirical relation is common for all deformation percentages. This relationship is valid within the band of hardness values $( \pm 7.5 \%)$ within the line contour. The strain values on or near to the fit line $(\mathbf{B H N}=\mathbf{4 0 . 1 1}(\overline{\boldsymbol{\varepsilon}})+\mathbf{8 5 . 0 2})$ will yield accurate hardness values. A more accurate 
relationship can be obtained with more experimental trials.

\section{Conclusions and Recommendations}

From the present work the following conclusions can be drawn:-

1- Compare experimental and finite element results explain that there is good agreement with maximum error of $7.7 \%$.

2- It was found that average surface hardness increase with increasing deformation percentage.

3- Applying the "Image J" program for estimating the average grain size prove that the average grain size decreasing when deformation percentage increasing.

4- Now it is possible to predict the hardness distribution at the design stage itself, without performing experiments, one can monitor and control the cold upset forging process in the design stage itself during relationship between hardness and effective strain which it found that the hardness varies in linear proportion with effective strain for all the deformation percentages and this follows an empirical relation, $\mathrm{BHN}=\mathbf{4 0 . 1 1}(\overline{\boldsymbol{\varepsilon}})+\mathbf{8 5 . 0 2}$

\section{REFERENCES}

[1] Luka Dugandzic, "Hot Impression Die Forging Process Parameter Development for Production of 6061 Aluminum Alloy Medallions", Report, California Polytechnic State University, (2004).

[2] Harshil Parikh, Bhavin Mehta and Jay Gunasekera, "Forging Process Analysis and Preform Design", Report, Department of Mechanical Engineering- Ohio University, (2000).

[3] J. Beddoes, and M. J. Bibby, "Principle of Metal Manufacturing Process", Antony Rowe Ltd, Eastbourne, (2006).

[4] F. Fereshteh-Saniee and M. Jaafari, "Analytical, Numerical and Experimental Analysis of the Closed-Die Forging", Journal of Materials Processing Technology, pp.334-340, (2002).

[5] K. Baskaran, and R. Narayanasamy, "Effect of Various Stress Ratio Parameters on Cold Upset Forging of Irregular Shaped Billets using Graphite as Lubricant under Plane and Triaxial Stress State Conditions", Materials and Design, pp.20892103, (2008).

[6] Andrew Jenner and Bradley Dodd, "Cold Upsetting and Free Surface Ductility", Journal of Mechanical Working Technology, pp.31-43, (1981).

[7] J. A. Schey, T.R. Venner and S.L. Takomana, "The Effect of Friction on Pressure in Upsetting at Low Diameter to Height Ratios", Journal of Mechanical Working Technology, pp.2333, (1982).
[8] D. Y. Yang, Y. Choi and J. H. Kim,, "Analysis of Upset Forging of Cylindrical Billets Considering the Dissimilar Frictional Conditions at Two Flat Die Surfaces", Int. J. Mach. Tools Manufact. Vol. 31, No. 3,pp.397-404, (1991).

[9] Mumin Sahin, Cem S. Cetinarslan and H. Erol Akata, "Effect of Surface Roughness on Friction Coefficients during Upsetting Processes for Different Materials", Materials and Design, pp. 633-640, (2007).

[10] J. Babu Rao, Syed Kamaluddin, J. Appa Rao, M. M. M. Sarcar and N. R. M. R. Bhargava, "Deformation Behavior of Al-4Cu-2Mg Alloy during Cold Upset Forging", Journal of Alloys and Compounds, pp.128-136, (2009).

[11] F. Soavi, L. Tomesani and O. Zurla, "Incipient Upsetting of Solid Cylinders Between Rigid and Elastic Tools", Int. J. Mech. Sci. Vol. 36, No. 7,pp.601-615, (1994).

[12] X. L. Hu and Z. R. Wang, "Numerical Simulation and Experimental Study on the Multi Step Upsetting of a Thick and Wide Flange on the End of a Pipe", Journal of Materials Processing Technology, pp.321-327, (2004).

[13] K. Baskaran and R. Narayanasamy, "An Experimental Investigation on Work Harding Behaviour of Elliptical Shaped Billets of Aluminium during Cold Upsetting", Materials and Design, pp. 1240-1265, (2008).

[14] K. Baskaran and R. Narayanasamy, " Some Aspects of Barrelling in Elliptical Shaped Billets of Aluminium during Cold Upset Forging with Lubricant ", Materials and Design, pp. 638-661, (2008).

[15] Shiro Kobayashi, Soo-Ik Oh and Taylan Altan, "Metal Forming and the Finite Element Method", Oxford University Press, Inc., (1989).

[16] E. Madenci and I. Guven, " The Finite Element Method And Applications In Engineering Using Ansys", Springer Science And Business Media Publishers, New York,(2006).

[17] ANSYS, "Solid Modeling And Meshing Guide", Releas Version 11.0

[18] J. Appa Rao, J. Babu Rao, Syed Kamaluddin, M. M. M. Sarcar and N. R. M. R. Bhargava, "Studies on Cold Workability Limits of Pure Copper using Machine Vision System and Its Finite Element Analysis", Materials and Design, pp. 2143-2151, (2009).

[19] ANSYS,"Basic Analyses Procedure Guide",Releas Version 11.0 .

[20] R. Ganesh Narayanan, M. Gopal, and A. Rajadurai," Influence of Friction in Simple Upsetting and Prediction of Hardness Distribution in a Cold Forged Product", Journal of Testing and Evaluation, Vol. 36, No. 4, (2008).

[21] J. Zrnik; S. V. Dobatkin and I. Mamuzi, "Processing of Metals by Severe Plastic Deformation (SPD) - Structure and Mechanical Properties Respond", METABK 47(3), pp. 211-216, (2008).

[22] L.-L. Gao, X.-H. Cheng, "Grain Refinement and Mechanical Properties of $\mathrm{Cu}-\mathrm{Al} 10 \%-\mathrm{Fe} 4 \%$ alloy", Materials Science-Poland, Vol. 25, No. 4, (2007).

[23] Greger M., Kocich R., Kuřetová B. and Vlček M., " Ultrafine Grained Copper by Equal Channel Angular Extrusion Processing", Acta Metallurgica Slovaca, pp.(561 - 569), (2007) 